\title{
Sonia Cherrad, Le Discours pédagogique féminin au temps des Lumières
}

\section{Elisa Biancardi}

\section{(2) OpenEdition}

1 Journals

\section{Edizione digitale}

URL: http://journals.openedition.org/studifrancesi/1339

DOI: ERREUR PDO dans /localdata/www-bin/Core/Core/Db/Db.class.php L.34 : SQLSTATE[HY000]

[2006] MySQL server has gone away

ISSN: 2421-5856

\section{Editore}

Rosenberg \& Sellier

\section{Edizione cartacea}

Data di pubblicazione: 1 décembre 2015

Paginazione: 591-592

ISSN: 0039-2944

\section{Notizia bibliografica digitale}

Elisa Biancardi, «Sonia Cherrad, Le Discours pédagogique féminin au temps des Lumières», Studi Francesi [Online], 177 (LIX | III) | 2015, online dal 01 décembre 2015, consultato il 08 janvier 2021. URL: http:// journals.openedition.org/studifrancesi/1339; DOI: https://doi.org/10.4000/studifrancesi.1339

Questo documento è stato generato automaticamente il 8 janvier 2021.

\section{(c)}

Studi Francesi è distribuita con Licenza Creative Commons Attribuzione - Non commerciale - Non opere derivate 4.0 Internazionale. 


\title{
Sonia Cherrad, Le Discours pédagogique féminin au temps des Lumières
}

\author{
Elisa Biancardi
}

\section{NOTIZIA}

SONIA CHERRAD, Le Discours pédagogique féminin au temps des Lumières, Oxford, Voltaire Foundation, 2015 («Oxford University Studies in the Enlightenment»), pp. 311.

1 Il volume, composto da quattro capitoli e da sintesi introduttive e conclusive, s'incentra su un corpus di scritti pedagogici femminili pubblicati nella seconda metà del Settecento francese ad opera delle già note Mmes Leprince de Beaumont, d'Épinay e de Genlis, nonché delle meno conosciute Mmes o Mlles de La Fite, de Monbart, de Miremont, d'Espinassy e Le Masson Le Goft, per dar luogo a una disamina comparativa delle loro proposte. Le direttrici su cui si muove l'analisi mettono via via l'accento sui generi letterari adottati dal corpus - spesso orientati verso forme dialogiche composite connotate da enciclopedismo e aperture filosofiche-(cap. I, «La naissance d'un discours pédagogique féminin»), sugli estremi della discussione teorica intorno agli schemi formativi tradizionali e alle innovazioni propugnate dalla modernità (II, «Les modèles éducatifs»), sui programmi disciplinari e le materie di studio da considerarsi irrinunciabili anche per le allieve (III, «Les savoirs féminins des Lumières») e, infine, sulle istanze socio-politiche ed economiche che le pedagogiste non hanno mancato di sollecitare sotto il velo delle loro finzioni narrative (IV, «Les fictions au miroir de la société des Lumières»). Emerge dall'indagine un quadro d'insieme in cui risalta la sostanziale comunanza d'intenti delle educatrici, non solo avvicinate dall'analogia delle loro scelte estetiche, ma anche dagli obiettivi, dalle idee di fondo e dalle tendenze che le hanno indirizzate. Tutte in effetti si collocano nel solco delle Lumières, ma ne interpretano le indicazioni a seconda dei propri convincimenti personali. Più riformiste che rivoluzionarie, accolgono ancora i retaggi del passato quando questi restano 
adeguati alla nuova società, ma sono pronte a dissociarsene in caso contrario, in nome di presupposti basilari quali l'ineludibilità formativa della riflessione e della ragione contro il prevalere dell'esercizio mnemonico, e la promozione entusiasta di un sapere autotelico e allargato, opposto a un ammaestramento unicamente utile e dunque limitato. Emergono anche - al di fuori dell'impressione d'incompiutezza legata qua e là a conclusioni un po' spicce riguardo al merveilleux e alle forme brevi-, i risultati ottenuti dal volume, fra cui la rivalutazione dell'apporto tanto pedagogico quanto letterario di queste illuministe francesi, e la chiara demarcazione del contesto storicosociale che ha visto nascere le loro proposte settecentesche, contesto ben distinto dai successivi scenari del secolo decimonono. Suscita però perplessità, a questo proposito, la scelta dell'autrice di esaminare il Magasin des enfants di Mme Leprince de Beaumont, fonte d'indispensabili raffronti, sull'unica base di una riedizione dell'Ottocento, che, come tutte le altre riedizioni di quel secolo, risulta aver alterato il testo originario per adattarlo a una mutazione ormai avvenuta di valori, criteri ed esigenze. 